\title{
A ASSISTÊNCIA ESTUDANTIL NO IFPR: A CONSTRUÇÃO DE UM OBJETO DE ESTUDO
}

\author{
STUDENT ASSISTANCE AT IFPR: PROPOSING A STUDY
}

Evelyn Raquel Carvalho ${ }^{1}$

Maria Sara de Lima Dias ${ }^{2}$

\begin{abstract}
RESUMO: Apresenta-se o Programa Nacional de Assistência Estudantil (PNAES) e sua interface com o Instituto Federal do Paraná (IFPR). Optou-se por uma metodologia de pesquisa exploratória em base de dados, estes cotejados com autores pertinentes e análise qualitativa. Observou-se que o PNAES atende aos seus objetivos ao possibilitar a permanência na instituição para quantidade expressiva de estudantes, que, de outra forma, não teriam condições de prosseguir sua formação. Como desafios, apontam-se: as equipes interdisciplinares nos campi não são completas; a burocracia dificulta a compreensão de editais; as inscrições, virtualizadas, demandam conhecimento e equipamentos tecnológicos, ambos insuficientes; a execução do programa nos campi é centralizada e divulgada no formato de bolsas e auxílios econômicos, em detrimento de outras possibilidades de atendimento, como inclusão digital e apoio pedagógico. Ainda, cortes de orçamento impactam sua execução e colocam em risco o apoio à saúde, o auxílio transporte, a alimentação e inscrição em eventos científicos.
\end{abstract}

Palavras-chaves: Programa Nacional de Assistência Estudantil. Instituto Federal do Paraná. Permanência discente.

ABSTRACT: The National Student Assistance Program (PNAES) and its interface with the Federal Institute of Paraná (IFPR) are presented. We opted for an exploratory research methodology, comparing and analyzing data from oficial websites with relevant in the database with relevant theories and authors. It was observed that the PNAES meets its goals by making it possible to remain in the institution for a significant number of students, who otherwise would not be able to continue their education. As challenges, we highlight: interdisciplinary teams are not complete; bureaucracy makes it difficult to understand the notices; the virtualized registrations demand knowledge and technological equipment, both insuficiente; the execution of the program is centralized and disseminated in the form of scholarships and financial aid, to the detriment of other possibilities of assistance, such as digital inclusion and pedagogical support. Budget cuts impact its execution and put health support, transportation assistance, food and registration at scientific events at risk.

Keywords: National Student Assistance Program. Federal Institute of Paraná. Student permanence.

\footnotetext{
${ }^{1}$ Assistente social, servidora no Instituto Federal do Paraná, campus Paranaguá (PR), doutoranda no Programa de Pós-Graduação em Tecnologia e Sociedade na Universidade Tecnológica Federal do Paraná (UTFPR), e-mail: evelyncarvalho@alunos.utfpr.edu.br

${ }^{2}$ Docente e coordenadora do Programa de Pós-Graduação em Tecnologia e Sociedade na Universidade Tecnológica Federal do Paraná, pós-doutora em Psicologia pela Universidade Autônoma de Barcelona, e-mailmariadias@professores.utfpr.edu.br
} 


\section{INTRODUÇÃO}

Este artigo é uma discussão inicial de uma pesquisa de doutorado em andamento no Programa de Pós-Graduação em Tecnologia e Sociedade (PPGTe) da Universidade Tecnológica Federal do Paraná (UTFPR). Ser assistente social em um Instituto Federal e trabalhar em um departamento ligado diretamente a um setor de apoio ao estudante motivou este estudo. Objetiva-se abordar o Programa Nacional de Assistência Estudantil (PNAES) em sua interface com o Instituto Federal do Paraná (IFPR).

O PNAES é um programa que, institucionalizado, ganha peso de política pública voltada para estudantes em situação de vulnerabilidade. O Programa busca possibilitar a permanência na instituição para uma quantidade expressiva de estudantes, que, de outra forma, não teriam condições de prosseguir sua formação. Reflete, nesse sentido, uma oposição à racionalidade neoliberal da exclusão educativa de parte da população e expressa um movimento de busca de uma educação para todos. O termo exclusão refere-se a um "processo complexo e multifacetado, uma configuração de dimensões materiais, políticas, relacionais e subjetivas. É um processo sutil e dialético, pois só existe em relação à inclusão como parte constitutiva dela”" (SAWAIA, 2011, p. 9).

O princípio político do acesso à educação no Brasil representa um espaço de promoção de direitos, cidadania e de justiça social. O Brasil é signatário de documentos como a Declaração de Jomtien ou Declaração Mundial sobre Educação Para Todos, que expressa recomendações para tornar realidade o direito à educação, estabelecido na Declaração Universal dos Direitos Humanos de 1948. Assim, demonstrar que o acesso à educação para todos ainda necessita de políticas para vulneráveis evidencia um campo de debate repleto de contradições, uma vez que se origina da busca de superação das desigualdades sociais que ameaçam a própria possibilidade educativa. A vulnerabilidade caracteriza a condição de grupos de indivíduos, pessoas ou famílias que estão em situação de exclusão social. Compreende-se que o termo vulnerabilidade não se aplica apenas à condição da ausência de renda, mas também a "fragilização de vínculos afetivos relacionais e de pertencimento social (discriminações etárias, étnicas, de gênero ou por deficiências, dentre outras)." (FONAPRACE/ANDIFES, 2019, p. 32).

Para visibilizar o PNAES na interface com o IFPR, parte-se de metodologia exploratória em base de dados, fundamentada em documentos normativos que respaldam o PNAES no IFPR, além da investigação dos portais virtuais dos 26 campi paranaenses. Apresentam-se, primeiramente, as legislações fundantes do Programa e pesquisas já realizadas sobre o tema; a 
seguir, discute-se o contexto do IFPR, os documentos normatizadores, campi e equipes conforme divulgados em sites de acesso público, além dos programas e projetos advindos da execução do PNAES na instituição. Na sequência, indicam-se nas considerações finais alguns resultados preliminares do estudo.

Tabela 1. Inter-relação entre objetivos do estudo e metodologia utilizada

\begin{tabular}{lll}
\hline Objetivo & metodologia & Procedimento \\
\hline 1-Apresentação do PNAES & estudo documental; & $\begin{array}{l}\text { estudo de documentos legais e sites } \\
\text { públicos; } \\
\text { 2-Interface entre PNAES e IFPR }\end{array}$ \\
$\begin{array}{l}\text { estudo documental e investigação } \\
\text { estudo de documentos legais } \\
\text { (editais, informações contidas no }\end{array}$ \\
& $\begin{array}{l}\text { site da reitoria e campi sobre a } \\
\text { execução da assistência estudantil) } \\
\text { análise do quadro de equipes } \\
\text { interdisciplinares presentes nos 26 } \\
\text { campi divulgados no site de cada }\end{array}$ \\
& campus. \\
\hline
\end{tabular}

FONTE: As autoras (2021).

Como primeiro passo, buscaram-se as bases legais que fundamentam o PNAES, como informações presentes nos sites de entidades que colaboraram para sua construção, como o Fórum Nacional de Pró-reitores de Assuntos Comunitários e Estudantis (FONAPRACE) e a Associação Nacional dos Dirigentes dos Institutos Federais (ANDIFES), além da União Nacional de Estudantes (UNE). Estudou-se, também, a Portaria Normativa no 39 de 2007, e o Decreto $n^{\circ} 7.234$ de 2010, os quais possibilitaram a criação do PNAES enquanto lei. Para apresentar o PNAES no IFPR, buscou-se investigar a concepção de assistência estudantil adotada pelo IFPR, através de informações contidas nos sites tanto da reitoria como de cada campus, verificando-se editais, informes e detalhamento das equipes interdisciplinares no ano de 2020.

\section{O PROGRAMA NACIONAL DE ASSISTÊNCIA ESTUDANTIL: IMPLEMENTAÇÃO, POSSIBILIDADES E DESAFIOS}

O PNAES é fruto de lutas por uma educação democrática e inclusiva, e sua construção envolveu diversos atores sociais, como o Fórum Nacional de Pró-reitores de Assuntos Comunitários e Estudantis (FONAPRACE) e a Associação Nacional dos Dirigentes dos Institutos Federais (ANDIFES), além da União Nacional de Estudantes (UNE).

O FONAPRACE, que atua desde 1987, engaja-se na luta pela assistência estudantil, reunindo pró-reitores de Universidades Federais (UFEs) e Centros Federais de Educação 
Tecnológica (CEFETs). Em seu regimento atual, aprovado em 2014, o FONAPRACE tem por finalidade contribuir para a "integração das UFEs e CEFETs na formulação de políticas de assistência estudantil que promovam o acesso, a permanência e a conclusão dos ensinos profissionais de nível médio e superior" (FONAPRACE, 2014, art. $3^{\circ}$ ). Sendo assim, o fórum vem somar forças na democratização do ensino público superior voltado para que os/as estudantes possam desenvolver seus cursos em condições dignas e de modo igualitário (FONAPRACE, 2014). A ANDIFES, criada em 1989, representa oficialmente as universidades federais junto ao governo federal, comunidade acadêmica e sociedade em geral, na busca da valorização e defesa do ensino superior público e de qualidade. Destaca-se que muitas legislações que se têm hoje sobre a assistência estudantil foram resultado de movimentos impulsionados pela ANDIFES e pelo FONAPRACE.

A educação está presente no caput do artigo 205 da Constituição Federal (BRASIL, 1988), que preconiza a igualdade de condições de acesso e permanência escolar (artigo 206, I). Da mesma forma, a Lei de Diretrizes e Bases da Educação (BRASIL, 1996) também alicerça a assistência estudantil quando coloca a igualdade de acesso e permanência como princípio e determina que a educação "[...] tem por finalidade o pleno desenvolvimento do educando, seu preparo para o exercício da cidadania e sua qualificação para o trabalho" (BRASIL, 1996, artigo 01). A mesma normativa ainda prevê a "vinculação entre a educação escolar, o trabalho e as práticas sociais” (BRASIL, 1996, artigo 02, inciso XVI). A lei 10.861 de 2004, que institui o Sistema Nacional de Avaliação de Ensino Superior (SINAES), estabelece a responsabilidade social da instituição no que se refere à sua contribuição em relação à inclusão social; e no inciso IX - "a política de atendimento aos estudantes" (BRASIL, 2004).

O Programa de Apoio a Planos de Reestruturação e Expansão das Universidades Federais (REUNI), instituído pelo Decreto 6.096 de 2007, volta-se para a ampliação do acesso e permanência do estudante no ensino superior (BRASIL, 2007, artigo $2^{\circ}$ ). O PNAES foi instituído através da Portaria Normativa n ${ }^{\circ} 39$, em 2007, no entanto, é somente a partir do Decreto Presidencial n 7.234, em 2010, que há a implementação do Programa, dando-lhe o peso de política. O PNAES tem como objetivos: democratizar as condições de permanência dos jovens na educação superior pública federal; minimizar os efeitos das desigualdades sociais e regionais na permanência e conclusão da educação superior; reduzir as taxas de retenção e evasão; contribuir para a promoção da inclusão social pela educação (BRASIL, 2010). Evidencia-se a execução do PNAES nas instituições de ensino através das 10 áreas indicadas no Decreto n 7.234 de 2010: estudantil; alimentação; transporte; atenção à saúde; inclusão digital; 
cultura; esporte; creche; apoio pedagógico; e acesso, participação e aprendizagem de estudantes com deficiência, transtornos globais do desenvolvimento e altas habilidades e superdotação (BRASIL, 2010).

Implementado em 2010, o PNAES é uma legislação recente, tratando-se de um debate novo no contexto acadêmico. Em busca inicial, foram encontrados na Biblioteca Digital Brasileira de Teses e Dissertações (BDTD) 116 trabalhos cujo tema é 'Política Nacional de Assistência Estudantil'; destes, 103 são dissertações e 13 são teses. Sobre a 'assistência estudantil', o panorama é de 311 trabalhos, sendo 278 dissertações e 33 teses. Quando se articula o tema PNAES aos Institutos Federais (IFs), a plataforma indica 39 estudos, sendo 35 dissertações e 4 teses, cujos temas mais recorrentes, segundo a BDTD, são: assistência estudantil, administração pública, alimentação escolar, bolsas e educação.

A assistência estudantil ganha destaque nas discussões promovidas pela comunidade acadêmica, além de tomar espaço na agenda governamental impulsionada pelo Decreto $\mathrm{n}^{\circ} 7.234$ de 2010, que colocou o PNAES no nível de política institucionalizada (DUTRA; SANTOS, 2017). Segundo o FONAPRACE, o avanço originado pelo decreto é a saída do PNAES de uma política de governo para uma política de Estado (FONAPRACE, 2012). Para Souza (2006), tanto a política pública, em geral, como a política social, em particular, são campos multidisciplinares e seu foco está na explicação do funcionamento da inter-relação Estado, política, economia e sociedade. Enfatiza-se que as políticas públicas obedecem a um fluxo de construção, sendo inicialmente desenhadas, formuladas e, posteriormente, materializadas em planos, programas, projetos, bases de dados ou sistema de informação e pesquisas. Durante a sua execução, são implementadas mediante acompanhamentos e avaliações (SOUZA, 2006).

Não obstante o amplo leque de possibilidades de ações do PNAES - algumas universais e outras direcionadas para estudantes em vulnerabilidade segundo critérios específicos - o Programa ainda é visto de modo polarizado ao recurso financeiro, executado por meio de 'bolsas' e 'auxílios'. Compreende-se por bolsa o recurso financeiro creditado ao estudante mediante participação em atividade pedagógica, como um projeto ou evento científico, por exemplo. Por sua vez, o auxílio estudantil não requer participação em projetos ou outras atividades complementares; como o próprio nome sinaliza, é um complemento repassado também como recurso financeiro para a manutenção do estudante (IFPR, 2020).

A associação da assistência estudantil ao repasse de bolsas e auxílios reflete-se nas pesquisas científicas, conforme apontam Zanin (2019), Antunes (2018), Santos e Marafon (2016), e Spricigo e Silva (2016), que destacam a excessiva valorização das bolsas em detrimento 
de outras possibilidades de ação da assistência estudantil, pouco debatidas. Daros (2016) concorda com os/as autores/as e afirma que, ainda que o PNAES não defina, em seu decreto, as formas metodológicas pelas quais as ações serão executadas, há uma forte tendência para as ações de transferência de renda. Neste sentido, trata-se de uma seara permeada pela ‘assistencialização' das políticas sociais no contexto na educação que se evidencia, por exemplo, em programas de auxílio à moradia, alimentação, transporte, entre outros (DAROS, 2016). A autora questiona a 'bolsificação' das ações como uma armadilha excludente, pois visa apenas o atendimento emergencial às necessidades dos estudantes, para que estes possam "manter-se" minimamente na cidade em que se situa a instituição de ensino. (DAROS, 2016, p. 37). Nesse contexto, Leite (2015), ao analisar as múltiplas determinações do PNAES através de documentos, considera que esta política é determinada e determinante, e se materializa fortemente pelas bolsas e auxílios financeiros com repasse de recursos e, desta forma, atende aos interesses do empresariado, fortalecendo o mercado. Ao naturalizar a pobreza sob a ideologia da igualdade de oportunidade, obscurecem-se as causas profundas da desigualdade social.

A burocratização da assistência estudantil é pesquisada por Pinto (2015), para quem os procedimentos tornam-se enrijecidos, pois pontuam um perfil para o/a bolsista, qual seja: majoritariamente feminino, com idade entre 18 e 24 anos, oriundo/a do interior e com renda de meio salário-mínimo per capita. Os estudos de Dias e Soares (2012) corroboram os achados de Pinto (2015) sobre os impactos do auxílio para estudantes em vulnerabilidade social, indicando que tais recursos, juntamente com a possibilidade de estágio ou tipo de trabalho no ambiente escolar, colaboram para a sua permanência na instituição e lhes agregam uma espécie de 'estatuto de estudante'. Pinto (2015) acrescenta três tipos de visão dos(as) estudantes sobre o PNAES: direito, auxílio aos vulneráveis, e estratégia para permanência - não só pelo viés financeiro - para integração à vida acadêmica. Considera-se a visão, enquanto estratégia de manutenção para permanência e integração na trajetória acadêmica, como um dos pilares presentes no PNAES, uma vez que o Programa tem, entre seus objetivos, "IV - articular programas e projetos de assistência estudantil às atividades de ensino, pesquisa e extensão; V contribuir para a construção dos meios necessários ao pleno desempenho escolar e acadêmico dos/as estudantes [...]” (BRASIL, 2010).

Apoio financeiro, garantia, acesso, meio para redução das desigualdades e tantas outras expectativas e visões são apontadas sobre PNAES. Os estudos de Zanin (2019) ressaltam os limites para a assistência estudantil, indicando que, apesar de ser concebida como um dos 
principais apoios para a permanência escolar, ela não é em si um fator que impeça a evasão no percurso acadêmico.

\section{O INSTITUTO FEDERAL E SUA INTERFACE COM O PNAES}

A Rede Federal de Educação Profissional Científica e Tecnológica (EPCT) foi originada através da Lei Federal n 11.892 de 29 de dezembro de 2008, e possui como objetivos a qualificação do ensino e da pesquisa, e a promoção do desenvolvimento científico e tecnológico. Os IFs foram criados pela mesma lei que instituiu a Rede EPCT em 2008 e possuem, entre suas finalidades, a oferta de cursos em diversas modalidades de ensino, com ênfase na qualificação técnica e tecnológica, visando o desenvolvimento socioeconômico local, regional e nacional (BRASIL, 2008).

A legislação vincula o processo educativo às demandas sociais do território, ao fortalecimento dos arranjos produtivos locais, com vistas às potencialidades de desenvolvimento. Segundo dados do Ministério da Educação (MEC, 2020), existem em funcionamento $38 \mathrm{IFs}$, presentes em todos os estados brasileiros, 2 Centros Federais de Educação Tecnológica (CEFET), a Universidade Tecnológica do Paraná (UTFPR), 22 escolas técnicas vinculadas às universidades federais e o Colégio Pedro II. Uma das particularidades dos Institutos é a verticalidade do ensino, sendo assim, a instituição contempla desde o ensino médio até cursos de graduação e pós-graduação, concentrando faixas etárias diferentes em seu processo educativo (MEC, 2020). Os IFs são atendidos pelo PNAES principalmente pela caracterização inclusiva a todos/as, mas especialmente para aqueles menos favorecidos socialmente.

Estudos sobre o PNAES têm sido realizados nos IFs, voltando-se para a análise dos seus impactos na evasão escolar e inclusão social, aspectos da política de assistência estudantil em campi específicos, e realçam também a necessidade da implementação desta política (ABREU, 2017; CANCELLA, 2018; ANTUNES, 2018). O Plano Nacional de Assistência Estudantil (ANDIFES, 2007) reafirma a necessidade do fortalecimento de ações e projetos ligados à assistência estudantil voltados para as instituições de ensino superior e salienta a necessidade de pessoal capacitado para a composição de equipes multidisciplinares e interdisciplinares. Para tanto, tornam-se prementes concursos públicos para servidores técnico-administrativos (assistentes sociais, psicólogos, nutricionistas, cozinheiros), conforme necessidade de cada instituição e região (ANDIFES, 2007, p. 17).

O FONAPRACE, em parceria com a ANDIFES, realizou em 2019 sua V Pesquisa Nacional de Perfil Socioeconômico e Cultural dos/as Graduandos/as das IFES, sendo 
contemplados 1.200.300 estudantes de 63 universidades públicas e 2 CEFETs - Minas Gerais e Rio de Janeiro. A pesquisa levantou o perfil dos estudantes abrangendo aspectos como moradia, situação de trabalho, vida acadêmica, atividades culturais, condições de saúde e buscou compreender dificuldades estudantis e emocionais (FONAPRACE; ANDIFES, 2019). Os resultados indicaram uma realidade marcada por múltiplas vulnerabilidades: 70\% dos estudantes possuem renda familiar de até um salário-mínimo e meio per capita; 51,5\% autodeclaram-se negros; 64,7 \% são oriundos de escolas públicas; 54,6\% são mulheres, e 49,4 \% ingressaram por vagas de cotas.

Em que pese o PNAES - ancorado nos pilares do acesso, permanência e êxito - buscar atender através da assistência estudantil campos cada vez mais ampliados de atenção ao estudante, como inclusão digital, acessibilidade, apoio pedagógico, bolsas e auxílios, entre outras demandas que indicam a necessidade de equipes com profissionais especializados para este atendimento (FONAPRACE; ANDIFES, 2019), a realidade aponta desafios a serem superados. A área da educação vem sendo fragilizada devido a cortes no financiamento anual de até 36\%, conforme o Decreto $\mathrm{n}^{\circ}$ 9.741, de 29 de março de 2019. Tais reduções afetam direta e/ou indiretamente o PNAES, uma vez que podem ser suspensos o apoio a transporte, alimentação, moradia, saúde, além das bolsas de assistência.

\section{A ASSISTÊNCIA ESTUDANTIL NOS CAMPI DO IFPR, SUAS EQUIPES, AÇÕES E PERFIL DA COMUNIDADE ATENDIDA}

No Paraná, estão em funcionamento 26 campi, atendendo 30.860 estudantes em cursos na modalidade presencial e a distância. Trata-se de 43 cursos técnicos presenciais, 11 cursos técnicos na modalidade a distância, 20 cursos superiores presenciais, 3 cursos de especialização na modalidade presencial e 1 a distância (IFPR, Portal de Informações, 2020). Somam-se, ainda, os cursos de Formação Continuada e 1 curso presencial, ofertado no campus Paranaguá, de pósgraduação em nível de mestrado, no Programa Interdisciplinar em Ciência e Tecnologia.

A comunidade discente do IFPR é caracterizada pela reserva de vagas para grupos de inclusão social, de modo que $80 \%$ dos/as estudantes são cotistas, seja pela origem em ensino fundamental cursado em escola pública, pela cota racial ou pessoa com deficiência, ou pela questão de renda. Em consonância com o PNAES, a assistência estudantil é realizada no IFPR através da Resolução nº 11 de 2009, que define a Política de Apoio Estudantil como abrangendo um conjunto de estratégias direcionadas aos estudantes, pautada, segundo o Art.1, na "garantia 
de acesso, permanência e conclusão do curso de acordo com os princípios da Educação Integral (formação geral, profissional e tecnológica) em estreita articulação com os setores produtivos locais econômicos e sociais" (IFPR, 2009).

No IFPR, as ações da assistência estudantil são elaboradas, coordenadas, implementadas e avaliadas pela Diretoria de Assuntos Estudantis (DAES), cujos objetivos são "democratizar o acesso, garantir a permanência e o êxito no processo formativo do estudante, contribuindo para a formação integral e inclusão social de forma articulada com as atividades de Ensino, Pesquisa e Extensão" (IFPR, O que é assistência estudantil, 2020). Coordenada pela DAES e presente em todos os campi do IFPR, a Seção Pedagógica e de Assuntos Estudantis (SEPAE) é vinculada às ações da Assistência Estudantil e acompanha todos/as os/as estudantes, independentemente de serem bolsistas ou não. A equipe é composta por corpo interdisciplinar que pode abranger profissionais de Psicologia, Pedagogia, Serviço Social, Técnico-Administrativo em Educação, entre outros. O foco da ação é colaborar para a permanência e sucesso acadêmico do/a estudante (IFPR, Portal da DAES, 2020). Entre suas ações voltadas para o atendimento ao estudante em sua integralidade, estão a divulgação de editais, seleção e o acompanhamento dos programas e projetos da assistência estudantil.

O Programa de Auxílio Complementar ao Estudante (PACE) visa, através do repasse financeiro, colaborar nos gastos de manutenção do estudante (moradia, alimentação, transporte, material escolar). O Projeto de Inclusão Social (PBIS), assim como o Projeto Estudante Atleta (PEA) e o Projeto Monitoria incentivam a participação de estudantes em projetos de ensino/pesquisa/extensão, esporte e ações de monitoria através do suporte financeiro. Tais iniciativas acabam por colaborar com a participação do/a estudante, uma vez que as atividades acontecem no contraturno às aulas, sendo assim, através dos recursos eles/as conseguem manter-se integralmente na instituição. Outro projeto da assistência estudantil é o Auxílio Eventos, que subsidia financeiramente a participação dos estudantes em eventos científicos (IFPR, Portal da DAES, 2020).

Em todos os projetos, estudantes são acompanhados/as sistematicamente em demandas que extrapolam a questão do rendimento acadêmico, procurando compreender, através das ações da equipe interdisciplinar, o contexto de vida. Para serem contemplados/as pelos PACE, PEA, Monitoria e PBIS, é necessário que seja deferido/a no processo de análise socioeconômica, que é realizado pelo/a assistente social da equipe SEPAE, considerando-se a documentação e informações cadastradas através da plataforma virtual do Sistema de Gerenciamento da Assistência Estudantil (SIGAE) do IFPR. Além disto, são considerados dados da renda familiar, 
tipo de vínculo empregatício, presença de doenças crônicas, distância da instituição de ensino, gastos mensais, entre outras informações. Considera-se que situações familiares, de saúde e comunitárias podem refletir no desempenho e na frequência escolar, de modo que, para o recebimento da bolsa, a frequência deve ser de, no mínimo, 75\% ao mês (IFPR, Portal SIGAE, 2020).

Ao acessar editais do ano de 2020 disponíveis no link 'Assistência estudantil' do site da reitoria do IFPR, observa-se uma excessiva burocratização no que tange a prazos, listas de documentos necessários para comprovação de composição familiar, renda e gastos, residência, que se configura, muitas vezes, como barreiras para muitos estudantes e suas famílias, que, diante de sua realidade fragilizada, não chegam a concorrer aos auxílios disponibilizados. Outro ponto é a inscrição aos editais ser limitada ao sistema virtual, com cadastramento de documentos on-line, através de digitalização e compactação de arquivos. Tal exigência exclui tanto pela falta de conhecimento de operacionalização das ferramentas computacionais como pela própria falta de equipamentos tecnológicos. Aponta-se que a divulgação no site das ações da assistência estudantil com enfoque na concessão de bolsas e auxílios reforça o viés econômico recorrente sobre o PNAES. Em pesquisa preliminar aos sites dos 26 campi paranaenses (IFPR, Portal de Informações, 2020), consultando-se os links 'Quem é quem', 'Técnicos Administrativos em Educação' e 'Fale Conosco', relacionaram-se na Tabela 2 os/as servidores/as que compõem a equipe da SEPAE:

Tabela 2. Composição das equipes SEPAE conforme site do campus.

\begin{tabular}{|c|c|c|c|c|c|c|c|}
\hline $\begin{array}{l}\text { FUNÇÃO/ } \\
C A M P I\end{array}$ & $\begin{array}{l}\text { ASSIST. } \\
\text { SOCIA } \\
\text { L }\end{array}$ & PED. & PSIC & $\begin{array}{l}\text { ASSIST. } \\
\text { ALUNOS }\end{array}$ & TAE ** & TIL*** & OUTROS \\
\hline Arapongas & N.I.* & N.I.* & N.I.* & N.I.* & N.I.* & N.I.* & N.I.* \\
\hline $\begin{array}{l}\text { Assis } \\
\text { Chateaubrian } \\
\text { d }\end{array}$ & $\begin{array}{l}01 \\
\text { (chefia) }\end{array}$ & 01 & 01 & 03 & 02 & 01 & - \\
\hline Astorga & 01 & 01 & 01 & - & - & - & - \\
\hline Barracão & N.I.* & N.I.* & N.I.* & 01 & N.I.* & N.I.* & N.I.* \\
\hline Campo Largo & 01 & 01 & - & 02 & 02 & 01 & - \\
\hline Cascavel & $\begin{array}{l}01 \\
\text { (chefia) }\end{array}$ & 03 & 01 & 04 & 03 & 01 & - \\
\hline Capanema & 01 & 01 & - & 01 & 01 & - & Enfermeira \\
\hline Colombo & 01 & 01 & 01 & 02 & 01 (chefia) & - & - \\
\hline $\begin{array}{l}\text { Coronel } \\
\text { Vivida }\end{array}$ & 01 & - & 01 & 01 & 01 & - & - \\
\hline Curitiba & 01 & 04 & 02 & 01 & 01 & - & $\begin{array}{l}\text { auxiliar } \\
\text { educacional }\end{array}$ \\
\hline Foz do Iguaçu & N.I.* & N.I.* & N.I.* & N.I.* & N.I.* & N.I.* & $\begin{array}{l}\text { chefia/formação } \\
\text { indefinida }\end{array}$ \\
\hline Goioerê & N.I.* & 01 & 01 & N.I.* & 01 & N.I.* & N.I.* \\
\hline
\end{tabular}




\begin{tabular}{|c|c|c|c|c|c|c|c|}
\hline Irati & - & - & - & - & - & - & $\begin{array}{l}\text { chefia sem } \\
\text { identificação }\end{array}$ \\
\hline Ivaiporã & $\begin{array}{l}01 \\
\text { (chefia) }\end{array}$ & 02 & 01 & 04 & 00 & 01 & - \\
\hline Jacarezinho & 01 & 03 & 01 & 02 & - & 01 & \\
\hline Jaguariaíva & - & - & - & - & - & - & $\begin{array}{l}\text { chefia/formação } \\
\text { indefinida }\end{array}$ \\
\hline Londrina & 01 & 02 & 01 & 03 & 02 & 01 & $\begin{array}{l}\text { chefia/assistente de } \\
\text { alunos }\end{array}$ \\
\hline Palmas & 03 & 03 & 01 & 02 & 02 & & chefia/Pedagogia \\
\hline Paranaguá & 02 & 03(chefia & 01 & 04 & 01 & 02 & - \\
\hline Paranavaí & N.I.* & N.I.* & N.I.* & N.I.* & N.I.* & N.I.* & N.I.* \\
\hline Pinhais & N.I.* & N.I.* & N.I.* & N.I.* & N.I.* & N.I.* & N.I.* \\
\hline Pitanga & $\begin{array}{l}01 \\
\text { (chefia) }\end{array}$ & - & 01 & & 01 & - & - \\
\hline $\begin{array}{l}\text { Quedas do } \\
\text { Iguaçu }\end{array}$ & N.I.* & N.I.* & N.I.* & N.I.* & N.I.* & N.I.* & chefia/docente \\
\hline $\begin{array}{l}\text { Telêmaco } \\
\text { Borba }\end{array}$ & 01 & $\begin{array}{l}02 \\
\text { (chefia) }\end{array}$ & 01 & - & - & 03 & - \\
\hline Umuarama & 01 & 02 & - & 04 & 03 & 02 & - \\
\hline $\begin{array}{l}\text { União } \quad \text { da } \\
\text { Vitória }\end{array}$ & - & 01 & - & 01 & 01 & - & - \\
\hline TOTAL: & 19 & 31 & 15 & 35 & 22 & 13 & 08 \\
\hline
\end{tabular}

FONTE. As autoras (2020). *N.I=Não informado. ** TAE=Técnico/a Administrativo em Educação. ***TIL= Tradutor e Intérprete de Libras.

O levantamento indicou que psicólogos/as, assistentes sociais e pedagogos/as compõem 46,42\% das equipes da SEPAE. Alguns campi, como Foz do Iguaçu e Quedas do Iguaçu, informam no site somente o nome da chefia que compõe a equipe. Outros campi não indicam a equipe, como nos casos do município de Arapongas, Paranavaí e Pinhais, sendo este, também, um dado importante de pesquisa. Observou-se que não há padronização no modo de relacionar os/as servidores/as na página de cada campus, sendo as funções presentes na Seção Pedagógica e de Assuntos Estudantis: assistente social, técnicos/as administrativos/as em educação (TAE), assistente de alunos, pedagogo/a, psicólogo/a, e tradutor e intérprete de Língua Brasileira de Sinais -LIBRAS (TIL). Em alguns casos, chefias, enfermeira e auxiliar educacional estão também presentes compondo a equipe.

Conforme apontado, trata-se da primeira aproximação com os documentos normativos e o campo de estudo impulsionado pela atuação na política de assistência estudantil em um instituto federal. Salienta-se que a pesquisa é aprovada pelo Comitê de Ética em Pesquisa da Universidade Tecnológica do Paraná CAAE: 39858520.3.0000.5547- parecer 4.472.452 .

\section{CONSIDERAÇÕES FINAIS}

O levantamento bibliográfico apontou que há insuficiência de estudos sobre o impacto do PNAES nos IFs, mas evidencia-se que a execução dessa política de atenção discente tem 
colaborado para que estudantes permaneçam e concluam suas formações. A materialização dessa atenção se expressa através de auxílio transporte, moradia e alimentação, apoio pedagógico, saúde, creche, além de subsídios para participação em projetos de pesquisa e eventos científicos. A assistência estudantil colabora para a inclusão de parcela significativa de estudantes vulneráveis, fazendo com que permaneçam na instituição e participem de atividades que de outra forma estariam impedidos. A divulgação da assistência estudantil centralizada no aspecto econômico encobre outras possibilidades de ação deste programa, tais como acompanhamento pedagógico, inclusão digital e acolhimento, conforme disposto na própria legislação de criação do PNAES.

Destacam-se desafios relacionados com a burocratização, exigência de documentações complexas e inscrições limitadas a preenchimento de plataformas digitais, que demandam aparato e conhecimento tecnológico. As equipes interdisciplinares descritas nos sites dos 26 campis apontam composições variadas em número e especialidade, sendo que, em algumas localidades, a equipe composta por apenas 1 pessoa impacta diretamente no atendimento discente. Esta política vem sofrendo cortes de orçamento, o que influencia diretamente a sua execução e coloca em risco suportes fundamentais a quem deles necessita.

\section{REFERÊNCIAS}

ABREU, Renata Pacheco. As expressões da evasão dos estudantes atendidos [pela] Política de Apoio Estudantil do Instituto Federal de Educação, Ciência e Tecnologia do Estado do Paraná - Campus Londrina. 2017. Dissertação (Mestrado em Serviço Social e Política Social) - Universidade Estadual de Londrina, Londrina, 2017.

ANTUNES, Avelise Dias. Assistência Estudantil nos Institutos federais: da política à implementação. Dissertação (Mestrado em Educação) - Universidade Estadual de Campinas, Faculdade de Educação, Campinas, 2018.

ANDIFES. Associação Nacional dos Dirigentes das Instituições Federais de Ensino Superior.

Estatuto com adequações ao Novo Código Civil. Alterações aprovadas na LXIII reunião ordinária do Conselho Pleno, 21 de fevereiro de 2008, Salvador, BA. Disponível em: $<$ http://www.andifes.org.br/wp-content/uploads/2012/05/Estatuto Andifes.pdf $>$. Acesso em: 24 ago. 2020.

Página institucional, a Andifes. Disponível em: < http://www.andifes.org.br/institucional/andifes/>. Acesso em: 24 ago. 2020. 
Plano Nacional de Assistência Estudantil, 2007. Disponível em: < http://www.fonaprace.andifes.org.br/site/wp-content/uploads/2016/05/plano-nacionalde-assistc3aancia-estudantil-da-andifes3.pdf >. Acesso em: 24 ago. 2020.

BDTD. Biblioteca Digital Brasileira de Teses e Dissertações . Portal. Disponível em: $<$ https://bdtd.ibict.br/vufind/Search/Results?lookfor $=$ pol $\%$ C $3 \%$ ADtica + nacional + de + assis

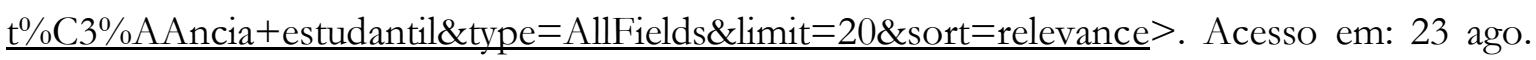
2020.

BRASIL. Decreto n 9.741, 29 de março de 2019. Altera o Decreto no 9711 de 15 de fevereiro de 2019 que dispõe sobre a programação orçamentária e financeira [...]. Diário Oficial da União, Brasília, DF. 29 mar. 2019.

Decreto 6.096 de 24 de abril de 2007. Institui o Programa de Apoio a Planos de Reestruturação e Expansão das Universidades Federais - (REUNI). Diário Oficial da União, Brasília, DF, 25 abr. 2007.

Decreto $n^{\circ}$ 7.234, de 19 de julho de 2010. Dispõe sobre o Programa Nacional de Assistência Estudantil-(PNAES). Diário Oficial da União, Brasília, DF, 20 jul. 2010.

Lei 10.861 de 14 de abril de 2004. Institui o Sistema Nacional de Avaliação Superior(SINAES) e dá outras providências. Diário Oficial de União, Brasília, DF, 15 de abr. de 2004. Lei 9.394 de 20 de dezembro de 1996. Estabelece as diretrizes e bases da educação nacional. Diário Oficial da União, Brasília, DF, 23 dez. 1996.

Lei n ${ }^{\circ}$ 11.892, de 29 de dezembro de 2008. Institui a Rede Federal de Educação, Profissional, Científica e Tecnológica, cria os Institutos Federais de Educação, Ciência e Tecnologia, e dá outras providências. Diário Oficial da União, Brasília, DF, 30 dez. 2008. . Constituição (1988). Constituição da República Federativa do Brasil de 1988.

Brasília, DF: Presidência da República, 05 out. 1988. Disponível em: $<$ http://www.planalto.gov.br/ccivil 03/constituicao/constituicao.htm >. Acesso em: 24 ago. 2020.

CANCELLA, André Santos. A oferta do esporte para os alunos com deficiência no Instituto Federal do Paraná - IFPR, campus Paranaguá: um movimento de reprodução ou resistência? 2018. Dissertação (Mestrado em Educação Física) - Universidade Federal do Paraná, Curitiba, 2018.

DAROS, Michelli Aparecida. Assistência estudantil e a evasão escolar no IFSP: elementos para reflexão. Conexões, Ciência e Tecnologia, Fortaleza, v. 10, n. 1, p. 32-43, mar. 2016. 
DIAS, Maria Sara de Lima; SOARES, Dulce Helena Penna. A escolha profissional no direcionamento da carreira dos universitários. Psicologia Ciência e Profissão, Brasília, v. 32, n. 2, p. 272-283, 2012.

DUTRA, Natália Gomes dos Reis; SANTOS, Maria de Fátima de Souza. Assistência estudantil sob múltiplos olhares: a disputa de concepções. Ensaio: Avaliação e Políticas Públicas em Educação, Rio de Janeiro, v. 25, n. 94, p. 148-181, jan./mar. 2017.

FONAPRACE. Fórum Nacional de Pró-reitores de Assuntos Comunitários Estudantis.

Regimento interno. João Pessoa, 2014. Disponível em: $<$ https://drive.google.com/file/d/0B6klljm4lUyJNVQzVU5oRHltNW8/view $>$. Acesso em: 24 ago. 2020.

(Org.); ANDIFES (Coord.). Revista Comemorativa 25 anos: História, memória e múltiplos $\quad$ olhares. $2012 . \quad$ Disponível em: http://www.proae.ufu.br/sitesites/proae.ufu.br/files/media/arquivo/revista fonaprace 25 an os.pdf. Acesso em: 24 ago. 2020.

V Pesquisa Nacional de Perfil Socioeconômico e Cultural dos/as Graduandos/as das IFES. Disponível em: <http://www.andifes.org.br/wpcontent/uploads/2019/05/V-Pesquisa-Nacional-de-Perfil-Socioecon\%C3\%B4mico-e-

Cultural-dos-as-Graduandos-as-das-IFES-2018.pdf> . Acesso em: 25 ago. 2020.

IFPR. Instituto Federal do Paraná. O que é assistência estudantil? Disponível em: $<$ https://reitoria.ifpr.edu.br/menu-academico/assistencia-estudante/>. Acesso em: 23 ago. 2020.

Portal da DAES. Disponível em: < https://reitoria.ifpr.edu.br/institucional/proreitorias/proens/dir-de-assuntos-estudantis-e-atividades-especiais/->. Acesso em: 17 ago. 2020.

Portal de Informações do IFPR. Disponível em: < //info.ifpr.edu.br/dados-geraisifpr/?tab=estrutura $>$. Acesso em: 15 ago. 2020.

Portal do Sistema de gerenciamento da Assistência Estudantil (SIGAE). Disponibilizado em: < https://sigae.ifpr.edu.br/>. Acesso em: 25 ago. 2020.

Resolução no 11 de 21 de dezembro de 2009. Aprova a Política de Apoio Estudantil do Instituto Federal do Paraná (retificada pela Resolução 53/2011). Disponível em: $<$ https://reitoria.ifpr.edu.br/resolucao112009/\#: :text=1\%C2\%B0\%20A\%20Pol\%C3\%ADt ica $\% 20$ de, estreita $\% 20$ articula $\% \mathrm{C} 3 \% \mathrm{~A} 7 \% \mathrm{C} 3 \% \mathrm{~A} 30 \% 20 \mathrm{com} \% 20 \mathrm{os} \% 20$ setores $>$. Acesso em: 25 ago. 2020.

JOHNSON, Allan. Dicionário de Sociologia. Rio de Janeiro: Jorge Zahar Ed., 1997. 
LEITE, Josimeire de Omena. As múltiplas determinações do Programa Nacional de Assistência Estudantil - PNAES nos governos Luiz Inácio Lula da Silva. Tese (Doutorado em Serviço Social) - Universidade Federal de Pernambuco, Recife, 2015.

MEC. Ministério da Educação. Portal da Rede Federal de Educação Profissional, Científica e Tecnológica. Disponível em: <http://redefederal.mec.gov.br/instituicoes $>$. Acesso em: 25 ago. 2020.

PINTO, Flavia Patrícia. Análise das políticas de permanência: estudo multicaso das Universidades federais do estado de São Paulo. 2015. Dissertação (Mestrado Profissional) Escola Paulista de Política, Economia e Negócios, Universidade Federal de São Paulo, Osasco, 2015.

SANTOS, Claudia Priscila Chuoel; MARAFON, Nelize Moscon. A Política de Assistência Estudantil na Universidade Pública Brasileira: desafios para o Serviço Social. Textos \& Contextos, Porto Alegre, v. 15, n. 2, p. 408-422, ago./dez. 2016.

SAWAIA, Bader. As artimanhas da exclusão: análise psicossocial e ética da desigualdade social. 2.ed. Petrópolis: Vozes, 2011.

SOUZA, Celina. Políticas públicas: uma revisão da literatura. Sociologias, Porto Alegre, n. 16, p. 20-45, dez. 2006.

SPRICIGO, Fabrício; SILVA, Mariléia Maria. Assistência estudantil e harmonização social: em análise o Programa de Atendimento ao Estudante em Vulnerabilidade Social do Instituto Federal de Santa Catarina. Revista Linhas, Florianópolis, v. 17, n. 35, p. 372-405, set./dez. 2016.

ZANIN, Alexsandra Joelma Dal Pizzol Coelho. Abandono e permanência escolar na educação profissional e tecnológica: olhares de trabalhadores da educação do Instituto Federal de Santa Catarina. Tese (Doutorado em Tecnologia e Sociedade) - Universidade Tecnológica Federal do Paraná, Curitiba, 2019. 